\title{
Call to add funding info to PubMed abstracts
}

$\mathrm{L}$ ook down, way down. Past the background information and the section describing methods. Past the tables full of numbers and all the pretty graphs. Have you come to the part with the conclusions? Sorry, your descent is not yet complete. You'll find it - if it even exists - at the very bottom, probably beneath the references.

It is here, in a research paper's cellar, where you may find information about who funded the study you just read about. And the researchers' conflicts of interest? You'll find those down here too (if they were disclosed).

But for some advocates of greater transparency in research, this just won't do. Information that reveals potential biases is too important to bury, they suggest. They want it to occupy prime real estate, way up top, in the article's penthouse. They want it in the abstract.

If you have even an atom of interest in science, you know that, in the research world, PubMed is a Very Big Deal. It's the National Library of Medicine's search engine, and it provides free access to more than 25 million citations from about 5600 scientific journals. It is used, millions of times a year, by doctors, scientists, librarians, students, journalists, policy makers, professors and the general public all over the world.

In a recent letter, 62 scientists and six organizations urged the National Library of Medicine to require all journals indexed in PubMed to include information about funding and competing interests in their abstracts. PubMed is a "precious global resource," they wrote in the letter, which was also sent to the National Institutes of Health. But many users never lay eyes on the bottom-dwelling tidbits on disclosure, for two reasons. They either don't have access to full articles or, if they do, they tend to skim abstracts.

"The scientists urged the [National Library of Medicine] to include financial information in abstracts because study results are often consistent with the interests of funders, so it would be

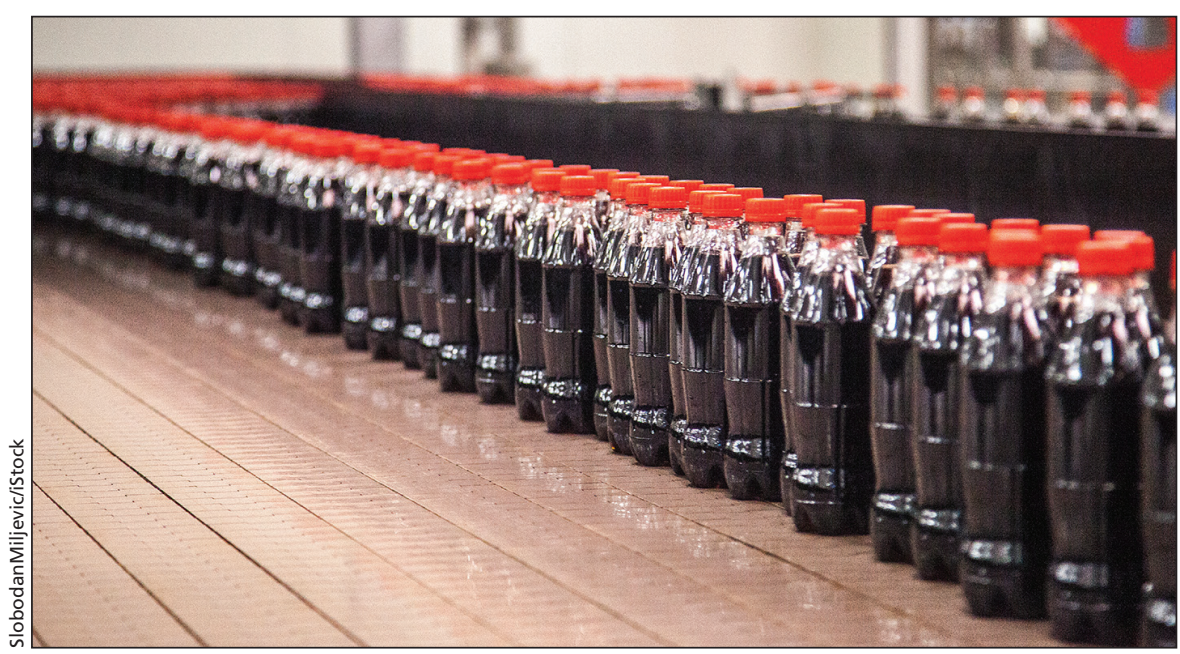

Many scientists want to know if a study about soda, for example, is funded by the soda industry. But should that information be in the study's abstract?

helpful to users of PubMed to have that information right in the abstracts," according to an email from Michael Jacobson, president of the Center for Science in the Public Interest, one of the organizations behind the letter.

Several members of the United States Senate lent support to the cause in a letter of their own. The senators argued that it has been shown, time and again, that companies often influence the outcomes of research they sponsor. "As the premier online database for scientific journals, and a public resource made possible with taxpayer dollars, PubMed has the unique opportunity and responsibility to make significant strides in improving the integrity of scientific research," stated the letter.

It goes without saying that journal editors are also big fans of scientific integrity, and few would object to efforts to improve it. Still, messing with the beloved PubMed, and the ever-popular abstracts in particular, is not a matter to be taken lightly.

"We at the $B M J$ think this would be a good idea," Dr. Elizabeth Loder, acting head of research for $B M J$, wrote in an email. "In practice there could be some challenges, however."

Some disclosure statements, noted Loder, are extremely long, especially for multicentre studies with many authors. If this additional information counted against the allowable PubMed character count, it would reduce the amount of study information the abstract could convey.

"This is important, because the abstract is all that many people see," wrote Loder. "The information it contains about the study helps people decide if they should retrieve the full article."

Indeed, some conflict-of-interest disclosures are many pages long, Dr. Jeffrey Drazen, editor-in-chief of the New England Journal of Medicine, wrote in an email. A possible solution, he suggested, would be to include a hyperlink to disclosure forms in the abstract.

This idea was also suggested by Betsy Humphreys, acting director of the National Library of Medicine, in an interview with Medscape Medical News. Simply plopping the disclosure text in the abstract, she noted, could affect datamining programs used by researchers to find index words in abstracts. "The conflict-of-interest information may have words, concepts and phrases that are potentially misleading," she said in the article. "You might come up with articles that aren't valid for the subject you're researching." - Roger Collier, CMAJ 